\title{
Lyme Disease: Features of Diagnostic and Management Strategies amongst Latvian General Practitioners
}

\author{
Viktorija Kutuzova ${ }^{1}$, Vladimirs Ivanovs ${ }^{2}$ and Gunta Tīcmane ${ }^{3}$ \\ 1. Rīga Stradiņš University, Dzirciema Street 16, Rīga LV-1007, Latvia \\ 2. University of Latvia, Raina Blvd 19, Rīga, LV-1586, Latvia \\ 3. Rīga Stradiņš University, Department of Family Medicine, Anniņmuižas Blvd 26a, Rīga LV-1007, Latvia
}

\begin{abstract}
Introduction: Lyme disease (LD)—disease caused by bacteria, spread by ticks. The most common sign is an erythema migrans that begins at the site of a tick bite about a week after it has occurred. LD has been treated by antibiotics. Aim: To figure out the most common LD diagnostic and treatment strategies among general practitioners (GPs) in Latvia and evaluate it basing on worldwide guidelines. Materials and methods: Quantitative cross-sectional study. Main material: GPs of different gender and age. Respondents (R) completed the survey voluntarily, anonymously. Data analysis done by using Microsoft Office Excel 2010 and SPSS 22.0. Results: In total, $126 \mathrm{R}$ were included. 32-Riga, 46-other cities and 48-rural areas. Analysis has shown dependence between percent of using guidelines and location of GP's practice. And 70\% of FD in Riga use LD guidelines in their practice, 20\% use lecture materials and $10 \%$ use their previous experience. Among GPs in other cities of Latvia 46.4\% use guidelines, 50\%—lecture materials and only 3.6\% use their previous experience. And $70.6 \%$ of GPs from rural areas base on lecture materials, $18.5 \%$ on guidelines and $11.1 \%$ on their previous experience. Analysis of knowledge about early symptoms of LD has shown that 30-45 years old GPs orient themselves in it better, then elder colleagues. Conclusions: GPs in cities use guidelines more often. Elder colleagues much worse orient themselves in theoretical information. I'm looking forward to creation of united LD diagnostic guidelines for Latvian GPs.
\end{abstract}

Key words: LD, diagnostics, treatment.

\section{Introduction}

The most common tick-borne disease in Latvia is the Lyme disease (LD) [1]. The burden of LD for individuals and society still remains high. Despite the availability of preventative measures the incidence of acute LD still remains significant [2]. According the Latvian Epidemiology Department results studies published in 2010, the percent of Lyme-infected Ixodes tics in Latvian forests was over 25\% [3]. Over the last decade there were 400-500 new cases of LD diagnosed in Latvia every year [4]. This research is very significant because the $L D$ is very common in Latvia, Europe and all over the world also there are usually some problems with diagnostics among general practitioners (GPs). We can notice that the tendency to

Corresponding author: Gunta Tīcmane, M.D., research fields: family medicine. spend vacation time outside in the open air has significantly grown during the last decade. This kind of behavior is very good if we are referring to living a healthier lifestyle, however it also can increase the risk of the transmission of tick-borne diseases [5]. The GP is the first doctor, the patient encounters when suspected of LD. It is the responsibility of the GP to be able to know how to distinguish the difference between this disease from the other tick-borne diseases and also how to effectively treat it right way [6].

\section{Aim}

The aim of this study was to determine the most common LD diagnostic and treatment strategies among GPs in Latvia and to evaluate it according to worldwide guidelines. The main hypothesis was: “The Latvian GPs in diagnostics and treatment of LD more often use the lecture materials and their previous 
experience then the guidelines”.

\section{Materials and Methods}

\subsection{Materials}

The design of the study is described as the quantitative cross-sectional study. The study group included 126 GPs of different genders, aged from 30 to 78 years (with the mean age of 55 years), who usually participate in conferences which are made by Rural Family Doctors Association of Latvia and Latvian Family Physicians Association. An originally created questionnaire was used to collect data from the respondents. Respondents completed the questionnaire voluntarily and anonymously. The questionnaire was about how do the GPs diagnose and treat LD in different clinical situations. For example, there was a question: "What would You do if You received patient's analyses with Borrelia burgdorferi IgM and IgG both high?” In general, 32 respondents were from Riga, 46 respondents were from other cities of Latvia and 48 respondents were from rural areas of Latvia. In total, 114 females and 12 males participated in the study.

\subsection{Statistical Analysis}

Data compilation and analysis were completed by using Microsoft Office Excel 2010 and SPSS 22.0 version (Crosstabulation, Chi-Square Test, Fisher's Exact Test). All analyses were performed on the $p$-value 0.05 . Values of $<0.05$ were considered to be statistically significant.

\section{Results}

All of the respondents have diagnosed and treated LD at least once in their practice and $25 \%$ of them have sent their patients to the Infectologist. In general, $17 \%$ of the respondents do not conduct the blood tests to their patients with the suspicion of LD. There is the correlation between this strategy and the doctor's age with $p=0.035$ (Fig. 1).

Only $49 \%$ of the respondents base their diagnosis on the anamnesis, physical examination and results of the blood tests of the patient. Another 51\% base their diagnosis only on one of the aspects. Most of them base their diagnosis only on the results of the blood tests in the first stage of disease.

There were 114 females and only 12 males among the respondents so that's not suitable for the normal distribution. Influence of gender was not statistically significant in this study. In general, according to this study, male GPs were chosen the same diagnostic and treatment strategies as female GPs.

Analysis of knowledge regarding early symptoms and management of LD has shown: 30-45 years old doctors are more aware and better informed about this, then their elder colleagues. Acrodermatitis chronica atrophicans and lymphocytoma are the late stage symptoms of LD [7-9]. Analysis of the results among

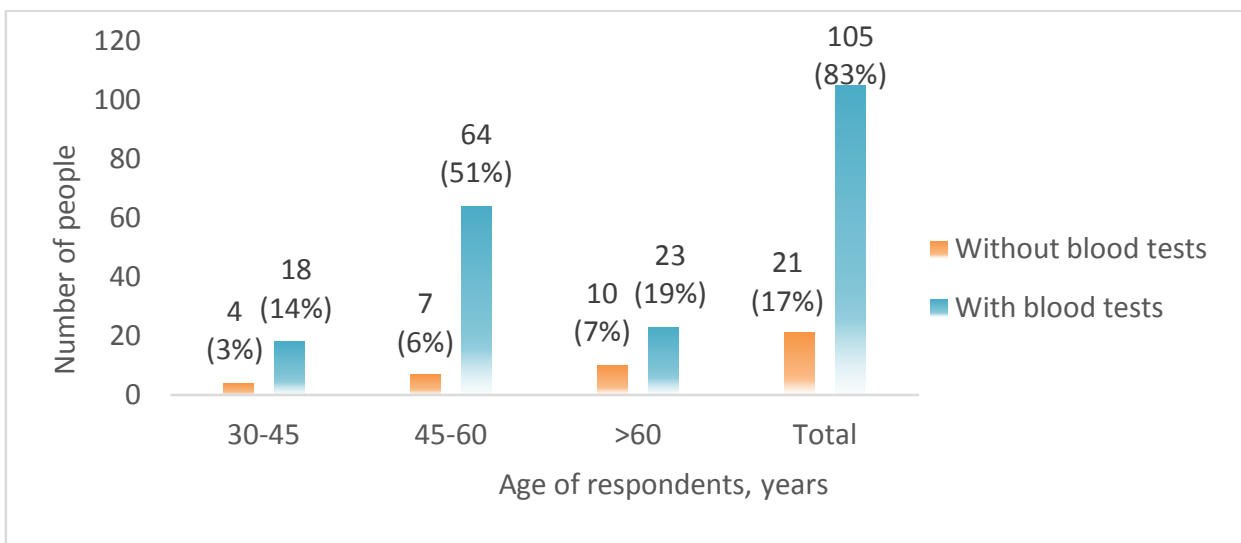

Fig. 1 Correlation between age and the starting treatment of early LD in patients without blood tests. 
age groups and their knowledge has shown, that in the age group 46-60 years old no one had chosen the correct answer as well as in the age group $>60$ years old (Table 1).

There was a question: What will you do, if patient's blood tests show negative Borrelia burgdorferi IgG and positive Borrelia burgdorferi IgM? In total, 70\% of the respondents gave the answer: "I will start the antibacterial therapy, because the diagnosis is clear". Only $30 \%$ of the respondents answered, that they will assign the Western blot or Immunblot blood tests to confirm the diagnosis. Proceeding from this and also according to this survey, only $31 \%$ of the respondents know what does the Borrelia burgdorferi IgM immune serologic cross reactions mean.

First line agent for LD among 92\% of Latvian GPs is Doxycycline. Another 8\% choose Amoxicillin and Azythromycin for treatment of LD in early stages (Fig. 2). The optimal course of Doxycycline for early LD chosen by GPs is 14-21 days (Fig. 3). It actually coincides with the worldwide evidence-based accepted course [10].

Mostly Latvian GPs do not treat the second and the third stages of LD and $73 \%$ of them direct their patients to the neurologist and $27 \%$ of them direct the patient to the infectologist.

Analysis has shown dependence between percent of using guidelines and location of GP's practice ( $p=0.016$ )

Table 1 Correlation between the knowledge regarding early symptoms of LD and the age of the respondents.

\begin{tabular}{|c|c|c|c|c|c|c|c|}
\hline \multirow{4}{*}{$\begin{array}{l}\text { Acrodermatitis chronica } \\
\text { atrophicans }\end{array}$} & Age group & Know & $\%$ & Do not know & $\%$ & Total & $\%$ \\
\hline & $30-45$ years & 12 & 63.4 & 10 & 35.7 & 22 & 100 \\
\hline & 46-60 years & 0 & 0 & 71 & 100 & 71 & 100 \\
\hline & $>60$ years & 0 & 0 & 33 & 100 & 33 & 100 \\
\hline \multirow[b]{2}{*}{ Lymphocytoma } & $30-45$ years & 6 & 4.8 & 16 & 95.2 & 22 & 100 \\
\hline & 46-60 years & 0 & 0 & 71 & 100 & 71 & 100 \\
\hline
\end{tabular}

Fig. 2 First line agents for Lyme disease chosen by Latvian general practitioners.
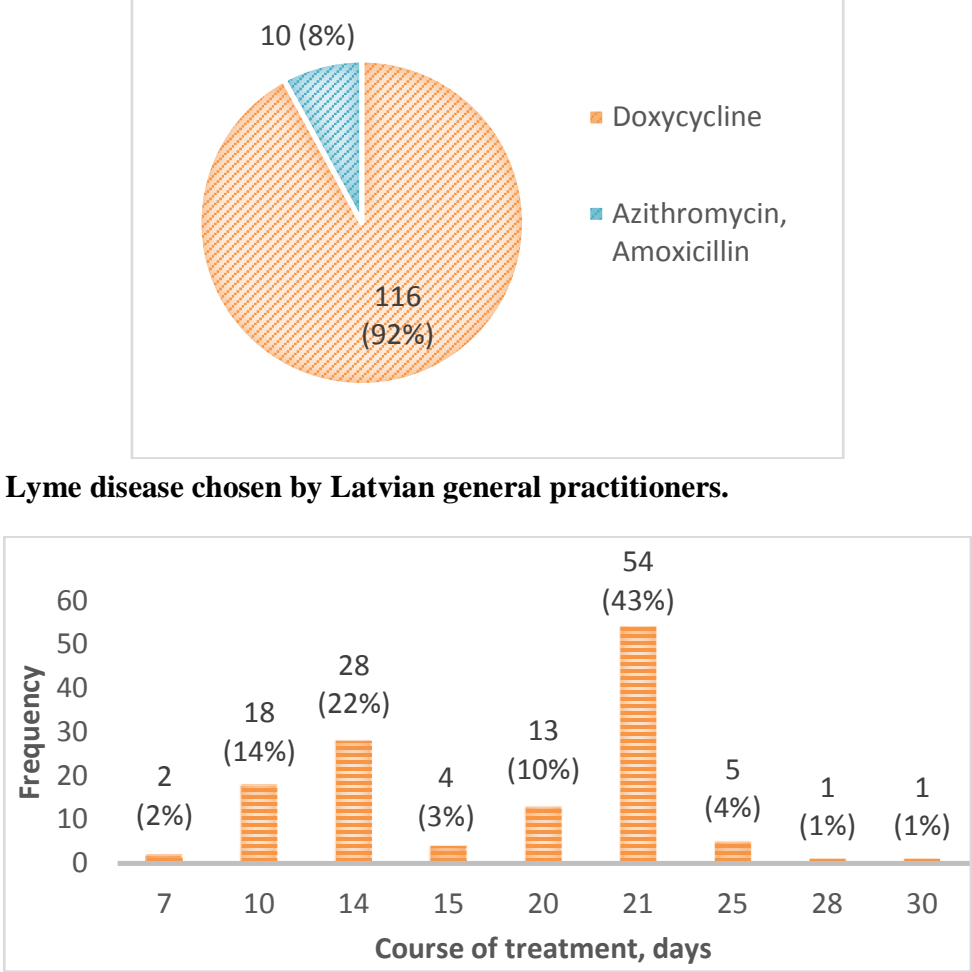

Fig. 3 Course of doxycycline for early Lyme disease chosen by Latvian general practitioners. 


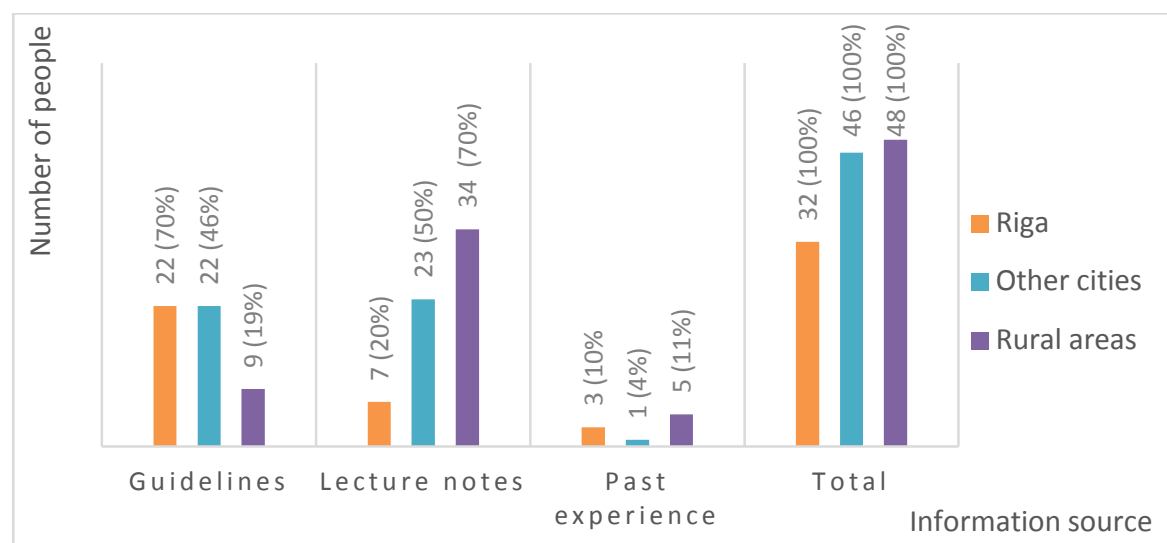

Fig. 4 Correlation between usage of guidelines and location of GP's practice in Latvia.

(Fig. 4). In total, 70\% of GPs in Riga use guidelines in their practice, $20 \%$ use lecture materials and $10 \%$ use their previous experience. Among GPs in other cities of Latvia $46 \%$ use guidelines, $50 \%$ use lecture materials and only $4 \%$ use their previous experience. $71 \%$ of GPs, who work in rural areas base on lecture materials, $18 \%$ on guidelines and $12 \%$ on their previous experience.

\section{Discussion}

There are four major problems from the GP's side. First, Latvian GPs have a tendency to send the patient to the infectologist (specialist) in situations when they can actually solve the problem on their own. According to this study, Riga has the largest percent of GPs who referred their patients to the infectologist (specialist). This could be explained by the fact, that in rural areas, the GP has to be able multi-task their duties: they can be a gynecologist, cardiologist, or even an infectologist (specialist). However, in Riga there is such a large number of medical specialists plus better transport connection in Riga that the GP can focus on being the "dispatcher" to his patient.

Moreover, GPs in Latvia are inclined to spend government funding unnecessarily on analyzing patients in the early stages of LD. In this case, the age of GP often plays a factor. For example, older GP tend not to conduct unnecessary blood tests for patient. This may be explained by fact that younger GPs appear to be less conscious in the diagnosis and attempt to discover through blood tests analysis.

Second, a common mistake of GPs is that they confuse an allergic reaction to a tick's bite which appears a few days after the bite accompanied with a true erythema migrans. Thus, the GPs often prescribe unnecessary treatment with antibiotics that can result with bacterial resistance. In addition, the prescription of unnecessary antibacterial medications can result in the patient experiencing a decrease in health due to the side effects of the medication [11, 12].

In my research, I discovered that there was one similar study in Quebec (Canada). It showed a similar pattern when it came to implementing the treatment of patients in cases where Borrelia burgdorferi IgM is positive. There were similar results when doctors arranged analyzes and treatment a few days after the tick bite. As a result, Canadian GPs conducted unnecessary analyzes to "fresh-bitten" tick bitten patients while freely spending government funding in vain. The strategy of management of early LD amongst Canadian GPs in $20 \%$ of cases was shown as unsuccessful and mistreated according to worldwide guidelines. In comparison with the Quebec study, Latvian GPs cope very well with the treatment of LD according to this study. In the end of the Quebec's study, the government proposed that GPs pay closer attention to patient care and to participate in additional course studies about LD. The majority of the GPs agreed to participate [13].

Third, a diagnostic problem amongst GPs in Latvia 
is the tendency "to treat analyzes" of their patients. What this means is that the GPs do not take into account the anamnesis and the results of the physical examination of their patients and only predict required treatment based on numbers written on a paper. In theory, the perfect diagnostic strategy is to take into account the anamnesis, physical examination and the results of analyzes of the patient and not to forget about the holistic approach.

The fourth problem in diagnostic among GPs in Latvia is that the Western blot test is too expensive. This is the reason why this study has shown a significantly low percent of using this test among GPs.

Epidemiologists tell us that the Latvian population is getting older and the population of GPs is getting older too [14]. Thus, the elder and more experienced GPs used to use some old sources of literature and their own experience, but the younger ones lack experience, but they retain the information about diseases better and also have utilizing new technology like the internet in different languages as a resource tool. The offer is to create the united and adapted for Latvia guidelines in Latvian language for Latvian GPs considering the epidemiological, technical, clinical and financial situation in the state of Latvia.

\section{Conclusions}

The percent of doctors, who choose not to conduct blood tests, is growing proportionally based on the doctor's age. Younger colleagues tend to focus on theoretical information more often, than their elder colleagues. Most of the respondents consider, that if Borrelia burgdorferi IgM are high, the diagnosis of LD is clear. This does not match with any of the guidelines. So, Latvian GPs are unfamiliar with the serologic cross reactions with another diseases and this can lead to incorrect diagnoses. Although, the therapy for LD chosen by Latvian GPs mostly coincides with the worldwide guidelines [14]. GPs in cities use guidelines more often than the rural GPs. The main hypothesis of the research is mostly confirmed. However, I am looking forward to a united LD diagnostics and management guidelines for Latvian (or Baltic) GPs, as the knowledge and strategies used by doctors vary and can be insufficient in producing an appropriate course of action.

\section{References}

[1] Cameron, D. J., Johnson, L. B., and Maloney, E. L. 2014. "Evidence Assessments and Guideline Recommendations in Lyme Disease: the Clinical Management of Known Tick Bites, Erythema Migrans Rashes and Persistent Disease.” Expert Review of Anti-infective Therapy 12 (9): 1103-35. doi: 10.1586/14787210.

[2] Deutsche Borreliose-Gesellschaft. e.V. Am Planetarium 12, D-07743 [internet] Jena, Germany. [cited 30.11.2017]. Avaliable from: www.borreliose-gesellschaft.de.

[3] Myglanda, A., Ljøstada, U., Fingerled, V., Rupprecht, T., Schmutzhard, E., Steiner, I., European Federation of Neurological Societies. "EFNS Guidelines on the Diagnosis and Management of European Lyme Neuroborreliosis.” Eur J Neurol 17 (1): 8-16.

[4] Brouqui, P., Bacellar, F., Baranton, G., Birtles, R. J., Bjoe“rsdorff, A., Blanco, J. R., Caruso, G., Cinco, M., Fournier, P. E., Francavilla, E., Jensenius, M., Kazar, J., Laferl, H., Lakos, A., Lotric Furlan, S., Maurin, M., Oteo, J. A., Parola, P., Perez-Eid, C., Peter, O., Postic, D., Raoult, D., Tellez, A., Tselentis, Y., Wilske, B., ESCMID Study Group on Coxiella, Anaplasma, Rickettsia and Bartonella, European Network for Surveillance of Tick-Borne Diseases. 2014. "Guidelines for the Diagnosis of Tick-Borne Bacterial Diseases in Europe.” 10 (12): 1108-32.

[5] European Centre for Disease Prevention and Control. 2016. "A Systematic Literature Review on the Diagnostic Accuracy of Serological Tests for Lyme Borreliosis.” Stockholm: ECDC, pg. 3-25.

[6] Factsheet for Health Professionals-Lyme Borreliosis [internet]. ECDC; 2010.—[cited 27.12.2017.] Avaliable from:

http://www.ecdc.europa.eu/en/healthtopics/emerging_and _vector-borne_diseases/tick_borne_diseases/lyme_diseas e/factsheet/healthprofessionals/Pages/factsheet_health_pr ofessionals.aspx.

[7] Freedberg, I. M., Eisen, A. Z., Wolff, K., Frank Austen, K., Goldsmith, L A., and Katz, S. 2003. Fitzpatrick's Dermatology in General Medicine. 6th Edition. New York: McGraw-Hill.

[8] Ferrouillet, C., Lambert, L., Milord, F., Vibien, A., and Ravel, A. 2015. "Lyme Disease: Knowledge and Practices of Family Practitioners in Southern Quebec.” Can J Infect 


\section{Strategies amongst Latvian General Practitioners}

Dis Med Microbial 26 (3): 151-6. Avaliable from: https://www.ncbi.nlm.nih.gov/pmc/articles/PMC4507841 /.

[9] Kasper, D. L., Fauci, A. S., Hauser, S. L., Longo, D. L., Lameson, J. L., and Loscalzo, J. 2015. Harrison's Principles of Internal Medicine. New York, NY: McGraw-Hill Education.

[10] Steere, A. C. 2001. “Lyme Disease.” N Engl J Med. 345 (2): 115-25.

[11] Wormser, G. P., Ramanathan, R., Nowakowski, J., McKenna, D., Holmgren, D., Visintainer, P., Dornbush, R., Singh, B., and Nadelman, R. B. 2003. "Duration of Antibiotic Therapy for Early Lyme Disease.” Ann Intern Med. 138 (9): 697-704.

[12] Wormser, G. P. 2006. “Clinical Practice. Early Lyme
Disease.” N Engl J Med 354 (26): 2794-801.

[13] Wormser, G. P., Dattwyler, R. J., Shapiro, E. D., Halperin J. J., Steere, A. C. Klempner, M. S., Krause, P. J., Bakken J, S., Strle, F., Stanek, G., Bockenstedt, L., Fish, D., Dumler, J. S., and Nadelman, R. B. 2006. “The Clinical Assessment, Treatment, and Prevention of Lyme Disease, Human Granulocytic Anaplasmosis, and Babesiosis: Clinical Practice Guidelines by the Infectious Diseases Society of America.” Clin Infect Dis. 43 (9): 1089-134.

[14] Pārskati par atsevišksām infekcijas un parazitārajām slimībām: par 2010. gadu, par 2012. gadu, par 2013. gadu, par 2016. gadu [internet][cited 03.03.2018.]. Avaliable from: https://www.spkc.gov.lv/lv/statistika-un-petijumi/infekcij as-slimibas/valsts-statistikas-parskati/statistikas-parskati. 